\title{
Post-transcriptional small RNA pathways in plants: mechanisms and regulations
}

\author{
Hervé Vaucheret ${ }^{1}$ \\ Laboratoire de Biologie Cellulaire, Institut Jean-Pierre Bourgin, 1'Institut National de la Recherche Agronomique, \\ 78026 Versailles Cedex, France
}

\begin{abstract}
Small RNAs are riboregulators that have critical roles in most eukaryotes. They repress gene expression by acting either on DNA to guide sequence elimination and chromatin remodeling, or on RNA to guide cleavage and translation repression. This review focuses on the various types of post-transcriptional small RNA-directed pathways in plants, describing their roles and their regulations.
\end{abstract}

For a long period of time, DNA, the support of heredity, and proteins, the actors of the cellular machinery, have been considered the most important components of biological systems. By contrast, RNA was originally considered as an intermediate molecule, bridging the gap between DNA and protein (mRNA), or serving functional roles during splicing (snRNA) and translation (tRNA and rRNA). The recent discovery of an increasing number of large and small non-protein-coding RNAs with specific regulatory roles has changed our view of gene expression. In particular, 20- to 27-nucleotide (nt) small RNAs belonging to two classes, microRNAs (miRNAs) and short interfering RNAs (siRNAs), are known to play essential roles in the four Eukaryote kingdoms (protists, fungi, plants, animals), with the surprising exception of the yeast Saccharomyces cerevisiae. Small RNAs are involved in a variety of phenomena that are essential for genome stability, development, and adaptive responses to biotic and abiotic stresses. Their mode of action also is diverse. They guide DNA elimination during the formation of the macronucleus in protists and heterochromatin assembly in fungi and plants. They target endogenous mRNAs for cleavage and translational repression in plants and animals, and protect both plant and animal cells against virus infection through an RNA-based immune system. They also control the movement of transposable elements at the transcriptional and post-transcriptional level in plants and animals.

[Keywords: miRNAs; nat-siRNAs; plant; ta-siRNAs; viral siRNAs] ${ }^{1}$ Correspondence.

E-MAIL herve.vaucheret@versailles.inra.fr; FAX 33-1-30-83-30-99. Article and publication are at http://www.genesdev.org/cgi/doi/10.1101/ gad.1410506.

\author{
Cis-acting siRNAs as an RNA-based immune \\ mechanism and a silencing tool
}

Because small RNAs are repressors of gene expression, small RNA-mediated regulation is often referred to as RNA silencing, gene silencing, or RNA interference (RNAi). RNA silencing was discovered in plants more than 15 years ago during the course of transgenic experiments that eventually led to silencing of the introduced transgene and, in some cases, of homologous endogenous genes or resident transgenes (Matzke et al. 1989; Linn et al. 1990; Napoli et al. 1990; Smith et al. 1990; van der Krol et al. 1990). Gene silencing results from transcription inhibition (transcriptional gene silencing [TGS]) or from RNA degradation (post-transcriptional gene silencing [PTGS]), and correlates with the accumulation of siRNAs corresponding to the silenced promoter or to the degraded RNA, respectively (Hamilton and Baulcombe 1999; Mette et al. 2000). The production of virus-derived siRNAs was observed in response to virus infection (Hamilton and Baulcombe 1999), and plant mutants defective in PTGS were hypersusceptible to virus infection (Mourrain et al. 2000; Dalmay et al. 2001; Qu et al. 2005; Schwach et al. 2005). Studies in worm revealed that mutants defective in RNAi (the animal counterpart of PTGS) lose control of their transposable elements (Ketting et al. 1999). Altogether, these results suggested that the PTGS/RNAi pathway corresponds to an RNA-based immune system that allows cells to control endogenous (transposons) or exogenous (virus, transgenes) nucleic acid invaders through the action of cis-acting siRNAs, which derive from and target the invaders /Vance and Vaucheret 2001; Bartel 2004; Baulcombe 2004; Dunoyer and Voinnet 2005).

Biochemical dissection of the RNAi pathway in animals has revealed that long double-stranded RNAs (dsRNAs) are potent inducers of RNAi and that the pathway involves RNase III enzymes, which dice dsRNAs into siRNAs, and Argonaute enzymes, which slice single-stranded RNAs complementary to siRNAs (for review, see Du and Zamore 2005; Tomari and Zamore 2005). In Drosophila (Fig. 1), dsRNAs are processed into double-stranded siRNAs by DCR-2, an RNase III enzyme of the Dicer family. DCR-2 interacts with the dsRNAbinding domain protein $\mathrm{R} 2 \mathrm{D} 2$, resulting in asymmetric 

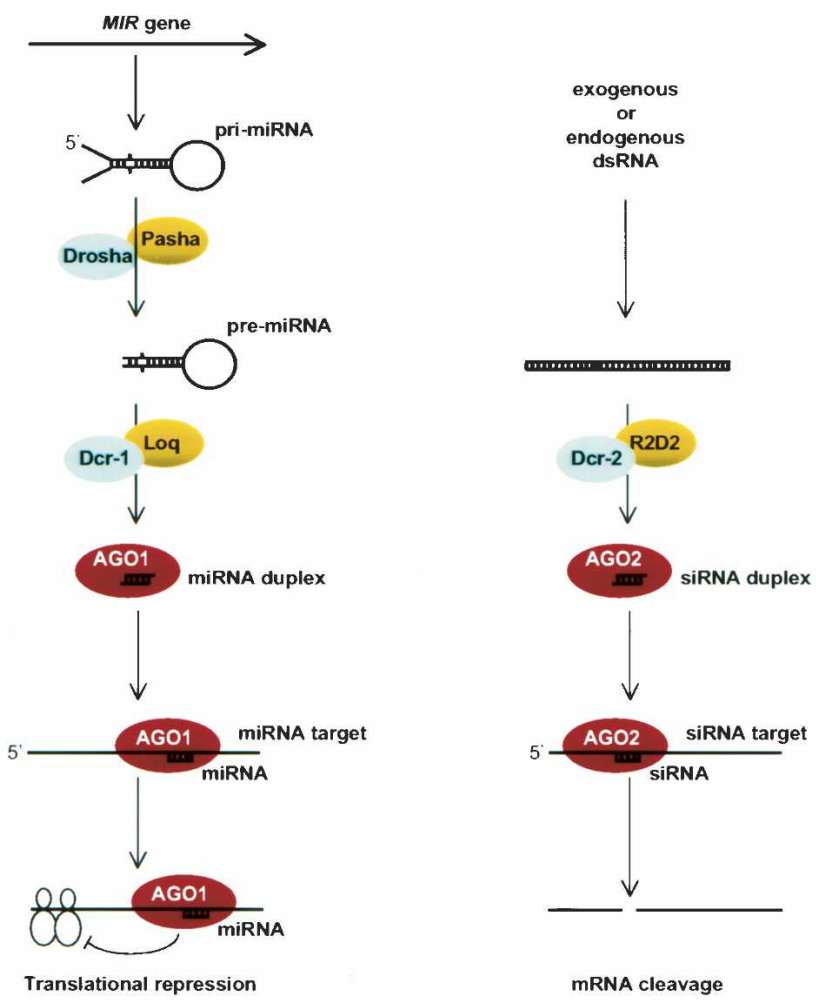

Figure 1. miRNA and siRNA pathways in animals. The pathways in Drosophila are shown as exampled, owing to the remarkable dissection of the pathway in this organism. A color code is used to indicate members of the same gene family. Translation repression and mRNA cleavage steps involve additional components that are not represented in this figure.

siRNA duplexes, with Dicer positioned at the less stable end and R2D2 at the other end. This asymmetry orients the loading of siRNA duplexes onto AGO2, a protein of the Argonaute family, which interact with Dicer enzymes. The strand of the siRNA duplex referred to as the passenger strand is cleaved by the RNA slicer activity of AGO2, allowing the other siRNA strand to pair with homologous mRNAs and guide AGO2-catalyzed mRNA cleavage. In addition to Dicer and Argonaute, some organisms (fungi, worms, plants) require RNA-dependent RNA polymerases to amplify RNAi. In most eukaryotes, Dicer, Argonaute, and RNA-dependent RNA polymerases are encoded by multigene families, allowing an extensive diversification of RNAi pathways. Although PTGS/RNAi pathways have not been fully elucidated in several organisms, the endogenous siRNA machinery now is used in many organisms as a powerful tool to knock-down endogenous gene expression in a tissue-specific or timely controlled manner.

In Arabidopsis, sequence-specific silencing of endogenous sequences can be achieved at low frequency using sense transgenes (S-PTGS) or at higher frequency using inverted-repeat transgenes (IR-PTGS) (Beclin et al. 2002). The high efficiency of IR-PTGS is due to the folding of transgene-derived RNAs into long, stable dsRNA structures (Smith et al. 2000), whereas S-PTGS relies on the ability of particular transgene loci to produce a yet unidentified species of single-stranded RNAs that can be converted into dsRNAs by RNA-DEPENDENT RNA POLYMERASE6 (RDR6), one of six RDRs in Arabidopsis, with the help of the coiled-coil protein SUPPRESSOR OF GENE SILENCING3 (SGS3) (Dalmay et al. 2000; Mourrain et al. 2000). The Arabidopsis Dicer enzyme that processes siRNAs during S-PTGS has not been fully elucidated, but it is likely to be DICER-LIKE4 (DCL4), which processes siRNAs from long dsRNAs during IR-PTGS (Dunoyer et al. 2005). Transgene-derived siRNAs are methylated by HUA ENHANCER1 (HEN1) (Boutet et al. 2003; Li et al. 2005; Yu et al. 2005) and guide sequencespecific ARGONAUTE1 (AGO1)-catalyzed mRNA cleavage (Morel et al. 2002; Baumberger and Baulcombe 2005; Qi et al. 2005). Additional components have been identified by forward and reverse genetic screens (Table1), including NUCLEAR RNA POLYMERASE IVa (NRPD1a), RNA-DEPENDENT RNA POLYMERASE2 (RDR2), SILENCING DEFECTIVE3 (SDE3), and WERNER EXONUCLEASE (WEX) (Dalmay et al. 2001; Glazov et al. 2003; Herr et al. 2005). The steps at which these proteins act in the PTGS pathway are still not fully understood. Interestingly, NRPD1a and SGS3 appear to be plant specific.

Part of the PTGS machinery (AGO1, HEN1, RDR6, and SGS3) also participates in the RNA-based immune response against cucumber mosaic virus (CMV) infection, a widely distributed virus that infects $>800$ plant species (Mourrain et al. 2000; Morel et al. 2002; Boutet et al. 2003), suggesting that transgene-derived RNAs produced during S-PTGS likely mimic viral RNAs during CMV infection and activate the corresponding RNAbased immune response. However, it is unlikely that all viruses activate the same response. Indeed, rdr6 mutants show hypersusceptibilty to CMV, a cucumovirus, and potato virux $X(P V X)$, a potexvirus, but not to turnip mosaic virus (TuMV), a potyvirus; turnip crinkle virus (TCV), a carmovirus; turnip vein clearing virus (TVCV) and tobacco mosaic virus (TMV), tobamoviruses; or tobacco rattle virus (TRV), a tobravirus (Dalmay et al. 2000, 2001; Mourrain et al. 2000; Qu et al. 2005; Schwach et al. 2005). In contrast, $r d r 1$ mutants impaired in a paralog of RNA-DEPENDENT RNA POLYMERASE6 show hypersusceptibility to TMV, suggesting that different post-transcriptional siRNA-mediated pathways are activated in response to infection by different viruses (Yu et al. 2003). Given the existence of 10 AGOs, four DCLs, and six RDRs in the plant model Arabidopsis (Morel et al. 2002; Schauer et al. 2002; Yu et al. 2003), the varying responses of different viruses to these mutations presumably reflect a diversification of siRNA pathways.

\section{MicroRNAs as endogenous regulators of gene expression}

Because transposon-, virus-, and transgene-derived siRNAs target the degradation of RNAs from which they derive, they are cis-acting siRNAs, and the immune phenomenon that relies on their action is referred to as autosi- 
Table 1. Plant proteins involved in small RNA-mediated post-transcriptional gene silencing

\begin{tabular}{|c|c|c|c|}
\hline Code & $\begin{array}{c}\text { Protein name } \\
\text { (alternative name) }\end{array}$ & Discovery & Function \\
\hline AGO1 & ARGONAUTE1 (DND) & $\begin{array}{l}\text { Developmental screen (Bohmert et al. 1998) } \\
\text { PTGS-deficient (Morel et al. 2002) }\end{array}$ & $\begin{array}{l}\text { RNA slicer (Vaucheret et al. 2004; } \\
\text { Baumberger and Baulcombe 2005; Qi } \\
\text { et al. 2005) }\end{array}$ \\
\hline AGO7 & ARGONAUTE7 (ZIP) & Developmental screen (Hunter et al. 2003) & RNA slicer (Adenot et al. 2006) \\
\hline DCL1 & $\begin{array}{l}\text { DICER-LIKE1 (CAF, EMB76, } \\
\text { SIN1, SUS1) }\end{array}$ & Developmental screen (Schauer et al. 2002) & $\begin{array}{l}\text { RNase III (Park et al. 2002; Reinhart et al. } \\
\text { 2002) }\end{array}$ \\
\hline DCL2 & DICER-LIKE2 & Reverse genetics (Xie et al. 2004) & $\begin{array}{l}\text { RNase III (Xie et al. 2004; Borsani et al. } \\
\text { 2005) }\end{array}$ \\
\hline DCL3 & DICER-LIKE3 & Reverse genetics (Xie et al. 2004) & RNase III (Xie et al. 2004) \\
\hline DCL4 & DICER-LIKE4 & $\begin{array}{l}\text { Reverse genetics (Gasciolli et al. 2005) } \\
\text { Developmental screen (Yoshikawa et al. } \\
\text { 2005) } \\
\text { PTGS-deficient (Dunoyer et al. 2005) }\end{array}$ & $\begin{array}{l}\text { RNase III (Dunoyer et al. 2005; Gasciolli } \\
\text { et al. 2005; Yoshikawa et al. 2005) }\end{array}$ \\
\hline HYL1 & $\begin{array}{l}\text { HYPONASTIC } \\
\text { LEAVES1 (DRB1) }\end{array}$ & $\begin{array}{l}\text { Developmental screen (Lu and Fedoroff } \\
\text { 2000) } \\
\text { Reverse genetics (Vazquez et al. 2004a) }\end{array}$ & $\begin{array}{l}\text { dsRNA-binding protein (Lu and Federoff } \\
\text { 2000; Hiraguri et al. 2005) }\end{array}$ \\
\hline DRB4 & $\begin{array}{l}\text { dsRNA-BINDING } \\
\text { PROTEIN4 }\end{array}$ & $\begin{array}{l}\text { Biochemistry (Hiraguri et al. 2005) } \\
\text { Reverse genetics (Adenot et al. 2006) }\end{array}$ & dsRNA-binding protein (Hiraguri et al. 2005) \\
\hline HEN1 & HUA ENHANCER1 & $\begin{array}{l}\text { Developmental screen (Chen et al. 2002) } \\
\text { PTGS-deficient (Boutet et al. 2003) }\end{array}$ & $\begin{array}{l}\text { RNA methylase (Li et al. 2005; Yu et al. } \\
\text { 2005) }\end{array}$ \\
\hline HST & HASTY & $\begin{array}{l}\text { Developmental screen (Telfer and Poethig } \\
\text { 1998) }\end{array}$ & Exp-5 ortholog (Park et al. 2005) \\
\hline NRPDla & $\begin{array}{l}\text { NUCLEAR RNA } \\
\text { POLYMERASE IVa (SDE4) }\end{array}$ & PTGS-deficient (Herr et al. 2005) & $\begin{array}{l}\text { DNA-dependent RNA polymerase (Herr } \\
\text { et al. 2005) }\end{array}$ \\
\hline RDR2 & $\begin{array}{l}\text { RNA-DEPENDENT RNA } \\
\text { POLYMERASE2 }\end{array}$ & $\begin{array}{l}\text { Reverse genetics (Xie et al. 2004) } \\
\text { PTGS-deficient (Herr et al. 2005) }\end{array}$ & $\begin{array}{l}\text { RNA-dependent RNA polymerase (Xie et al. } \\
\text { 2004; Herr et al. 2005) }\end{array}$ \\
\hline RDR6 & $\begin{array}{l}\text { RNA-DEPENDENT RNA } \\
\text { POLYMERASE6 } \\
\text { (SDE1/SGS2) }\end{array}$ & $\begin{array}{l}\text { PTGS-deficient (Mourrain et al. 2000) } \\
\text { Developmental screen (Peragine et al. 2004) }\end{array}$ & $\begin{array}{l}\text { RNA-dependent RNA polymerase (Dalmay } \\
\text { et al. 2000; Mourrain et al. 2000) }\end{array}$ \\
\hline SDE3 & SILENCING DEFECTIVE3 & PTGS-deficient (Dalmay et al. 2001) & RNA helicase (Dalmay et al. 2001) \\
\hline SGS3 & $\begin{array}{l}\text { SUPPRESSOR OF GENE } \\
\text { SILENCING3 } \\
\text { (SDE2) }\end{array}$ & $\begin{array}{l}\text { PTGS-deficient (Mourrain et al. 2000) } \\
\text { Developmental screen (Peragine et al. 2004) }\end{array}$ & RNA stabilizer (Yoshikawa et al. 2005) \\
\hline WEX & WERNER EXONUCLEASE & Reverse genetics (Glazov et al. 2003) & RNaseD exonuclease (Glazov et al. 2003) \\
\hline
\end{tabular}

Proteins involved in small RNA-mediated TGS are reviewed in Chan et al. (2005).

lencing (Bartel 2004). In contrast, miRNAs are endogenous small RNAs that are produced by genes distinct from the genes that they regulate, and, as such, miRNAmediated regulation is referred to as heterosilencing (Bartel 2004). The first miRNAs discovered were the small temporal RNAs (stRNAs) lin-4 and let-7, which were identified from a screen of Caenorhabditis elegans mutants exhibiting timing defects during larval development (Lee et al. 1993; Reinhart et al. 2000). These two single-stranded small RNAs appeared to be processed from imperfectly paired stem-loop precursor RNAs that are $\sim 70 \mathrm{nt}$ long, and the mature 21-nt stRNAs repressed gene expression by binding to multiple copies of partially complementary sites within the $3^{\prime}$ untranslated region (UTR) of their target mRNAs and repressing translation (Ambros 2004; Bartel 2004; Du and Zamore 2005; Kim 2005). After the discovery of stRNAs and siRNAs, the stage was set for the search for more noncoding small RNA and several laboratories successfully cloned numerous 21- to 24-nt RNAs from worm, fly, mouse, hu- man, and plants. The cloned small RNAs that displayed the characteristics of the original lin-4 and let-7 stRNAs-i.e., they are processed from partially folded stem-loop precursor RNAs that derive from genes that are distinct from the genes that they regulate-were collectively termed microRNAs. Most other endogenous small RNAs that do not fit this definition are collectively called siRNAs and are assumed to derive from long dsRNAs resulting from convergent transcription or from the action of RNA-dependent RNA polymerases. As a complement to cloning efforts, genetic approaches have made important contributions to the identification of miRNAs and their targets. For example, the first miRNAs functionally characterized in flies (bantam) and plants (miR319/JAW) were both identified from genetic screens (Brennecke et al. 2003; Palatnik et al. 2003).

Although both plant and animal miRNAs derive from partially folded stem-loop precursor RNAs, their biogenesis shows some differences (see Figs. 1, 2). Different animal miRNAs are often clustered within a single pre- 


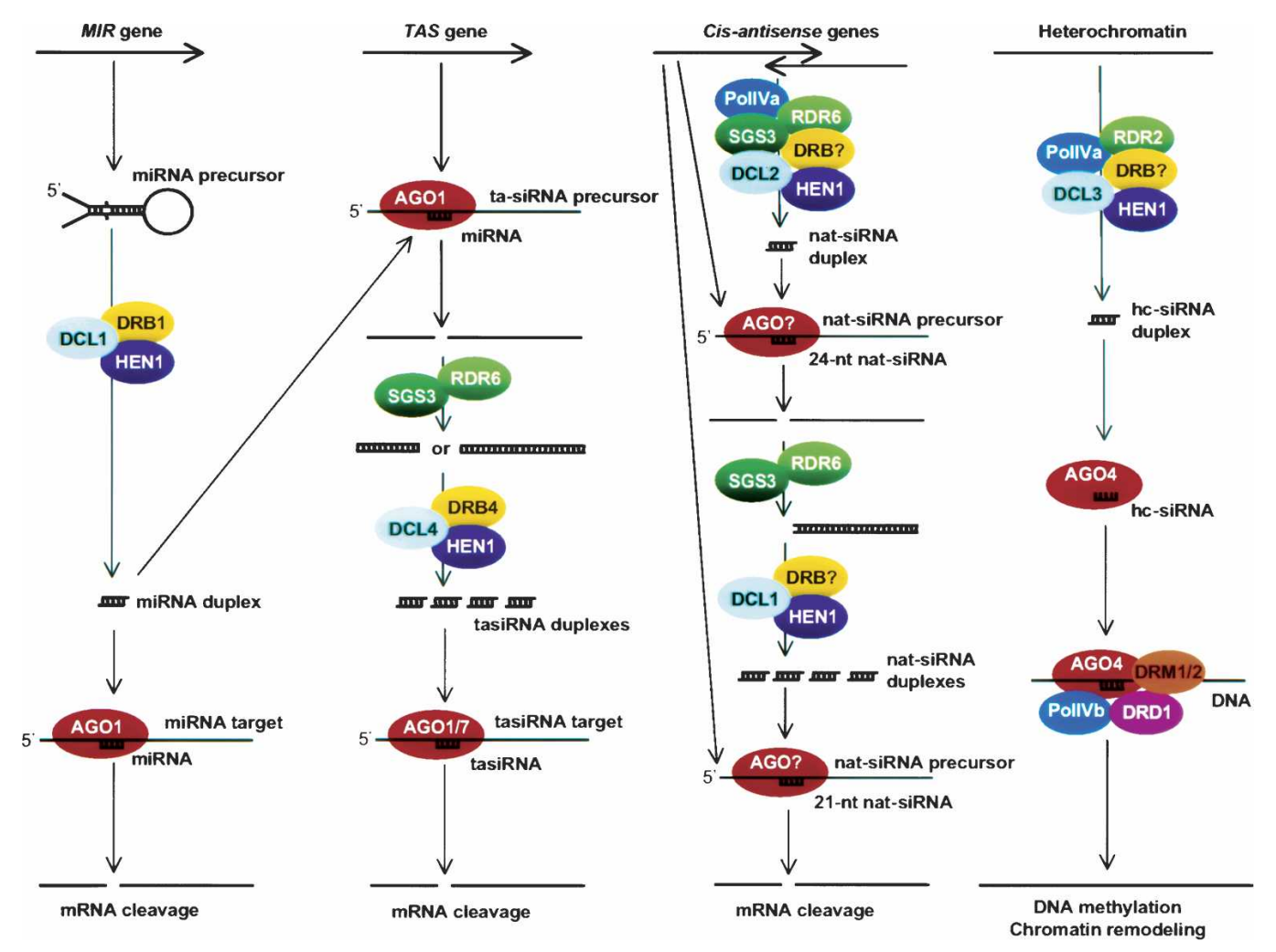

Figure 2. miRNA, ta-siRNA, nat-siRNA, and hc-siRNA pathways in plants. The same color code as in Figure 1 is used to indicate members of the same gene family. Question marks indicate that a member is likely to play a role in the pathway, but the identity of the protein has not been experimentally determined. HYL1 is referred to as DRB1 for clarity. The arrow between the miRNA and ta-siRNA pathways indicates that the miRNA pathway is required for the proper functioning of the ta-siRNA pathway. The multiple arrows emanating from the sense gene in the nat-siRNA pathway indicate that the RNA transcribed from this gene is used at various steps in this pathway. DNA modification steps in the hc-siRNA pathway involve additional locus-specific components that are not represented in this figure (for references, see Chan et al. 2005).

cursor RNA, whereas plant miRNAs derive from individual precursors (Ambros 2004; Bartel 2004; Du and Zamore 2005; Kim 2005). Animal miRNA precursors (pri-miRNAs) adopt fold-back stem-loops that are first cleaved by the RNase III Drosha on each arm of the stemloop to liberate the pre-miRNA (Ambros 2004; Bartel 2004; Du and Zamore 2005; Kim 2005), which is subsequently exported to the cytoplasm by Exp5 and cleaved by the RNase III Dicer to liberate the loop and the miRNA/miRNA* duplex that typically has two nucleotide $3^{\prime}$ overhangs, similar to siRNA duplexes (Ambros 2004; Bartel 2004; Du and Zamore 2005; Kim 2005). Both Drosha and Dicer are assisted in the cleavage processes by specific dsRNA-binding proteins; for example, Pasha and Loquacious, respectively, in Drosophila (Du and Zamore 2005). In plants, the length of fold-back stemloops generally is longer than that of animal stem-loops. DCL1 has both Drosha and Dicer functions and was found in the nucleus (Park et al. 2002; Reinhart et al. 2002; Papp et al. 2003; Kurihara and Watanabe 2004). DCL1 interacts with HYL1 to make both cuts within the miRNA precursor to liberate the miRNA/miRNA* duplex (Han et al. 2004; Vazquez et al. 2004a; Hiraguri et al. 2005). The mature miRNA is methylated by HEN1 (Yu et al. 2005), which also methylates siRNAs (Li et al.
2005). Methylation likely protects small RNAs from degradation and polyuridylation. Whether small RNAs are methylated in other kingdoms is not known. Like DCL1, HYL1 and HEN1 are found in the nucleus, suggesting that miRNA processing is essentially nuclear. HASTY is an ortholog of EXP5 and likely exports miRNA duplexes or mature miRNAs to the cytoplasm (Park et al. 2005). The accumulation of some miRNAs is not affected in hst mutants, suggesting either that these miRNAs are exported by other ways-for example, in association with AGO1-or that they act in the nucleus by targeting premRNAs, such as proposed for the targeting of partially spliced DCL1 mRNA by miR162 in Arabidopsis (Xie et al. 2003; Park et al. 2005).

The action of plant and animal miRNAs also shows striking differences (see Figs. 1, 2). Both associate with an Argonaute protein that is part of a ribonucleoprotein complex called RNA-induced silencing complex (RISC) (Bartel 2004). However, most animal miRNAs guide translational repression of their targets, which is accompanied by mRNA destabilization (Bagga et al. 2005; Lim et al. 2005), whereas all tested plant miRNAs guide AGO1-catalyzed mRNA cleavage (Llave et al. 2002; Kasschau et al. 2003), similar to AGO2-catalyzed mRNA cleavage by siRNAs in animals. MicroRNA-guided 
mRNA cleavage is not limited to plants. Indeed, miR196 guides the cleavage of HoxB8 mRNA in mice, presumably due to the unusually high degree of complementarity between the miRNA and its target (Yekta et al. 2004). On the other hand, it is unclear if miRNAs can guide translation repression in plants. Indeed, the initial proposal that miR172 guides translation repression of AP2 mRNA in plants (Aukerman and Sakai 2003; Chen 2004) has recently been revisited, and the unchanged level of AP2 mRNA in plants overexpressing miR172 has been attributed to increased AP2 gene transcription, which results from reduced negative feedback regulation by the AP2 protein (Schwab et al. 2005).

As opposed to animal miRNAs that only show limited complementarity with their targets at the $5^{\prime}$ end of the miRNA (the seed region), plant miRNAs show a high degree of complementarity with their targets (Ambros 2004; Bartel 2004; Du and Zamore 2005; Kim 2005). Indeed, the SCL genes were the first miRNA targets identified in plants because they exhibit full complementarity to miR171 (Llave et al. 2002; Rhoades et al. 2002). The high degree of complementarity together with conservation between monocots and dicots allowed a confident prediction of miRNA targets (Rhoades et al. 2002; Jones-Rhoades and Bartel 2004). In addition, plant miRNAs cleave their targets, allowing a simple validation of putative targets by 5' RACE (Llave et al. 2002; Kasschau et al. 2003). Most plant miRNAs exhibit four or less mismatches with their targets, with the exception of TCP targets that have up to five mismatches with miR319 (Palatnik et al. 2003), and these mismatches are usually located in the 3 ' region of the miRNA (Mallory et al. 2004; Parizotto et al. 2004; Schwab et al. 2005). Consistently, biochemical analyses using wheat germ extracts revealed that mutated targets with mismatches between positions 3 and 11 of the miRNAs were poorly cleaved, whereas mutated targets with mismatches at other positions were more efficiently cleaved (Mallory et al. 2004). The importance of near-perfect complementarity between miRNAs and their targets in plants was used to gain insight into their roles by expressing miRNA-resistant targets carrying silent mutations that disrupt the pairing but not the protein sequence, and looking at the changes induced by this loss of miRNAmediated regulation (Emery et al. 2003; Palatnik et al. 2003; Chen 2004; Mallory et al. 2004). The definitive demonstration of the relationship between a miRNA (miR168) and its target (AGO1) was achieved by rescuing miR168-resistant AGO1 plants with an artificial miRNA carrying compensatory mutations that restored pairing (Vaucheret et al. 2004).

As opposed to animal miRNAs that control a variety of phenomena (Carrington and Ambros 2003; Ambros 2004; Bartel 2004), about two-thirds of the known plant miRNAs control the expression of transcription factors that regulate crucial steps during plant development (Rhoades et al. 2002; Jones-Rhoades and Bartel 2004). Clues to the importance of miRNAs during development were revealed when mutants originally isolated in genetic screens for developmental defects turned out to be generally impaired at different points in the miRNA pathway (Table1). For example, the carpel factory (caf), short integuments1 (sin1), suspensor (sus1), and embryo defective76 (emb76) mutants all have mutations in the DCL1 gene (Schauer et al. 2002), and the first argonaute mutants (ago1) were identified in plants and named for the squid tentacle-like appearance of their leaves (Bohmert et al. 1998). Similarly, hyponastic leaves1 (hyl1), hua enhancer1 (hen1), and hasty (hst) were originally isolated as mutants impaired in hormone response, flower development, and the transition from juvenile to adult vegetative phase, respectively (Telfer and Poethig 1998; Lu and Fedoroff 2000; Chen et al. 2002). For recent reviews on the specific developmental roles of miR156, miR159, miR160, miR164, miR165/166, miR167, miR172, and miR319 in phase changes, leaf morphogenesis and polarity, root initiation, vascular development, transition from vegetative to reproductive growth, or floral differentiation, see Chen (2005), Jones-Rhoades et al. (2006), and Zhang et al. (2006a). Among the nontranscription factor targets of miRNAs, there are ATP-sulfurylases, superoxide dismutases, laccases, and ubiquitinconjugating enzymes (Jones-Rhoades and Bartel 2004). Two miRNAs-miR395, which regulates an ATP-sulfurylase, and miR399, which regulates a ubiquitin-conjugating enzyme-are induced by sulfate starvation and phosphate starvation, respectively, pointing to an adaptive role of miRNAs in stress response (Jones-Rhoades and Bartel 2004; Fujii et al. 2005).

\section{Trans-acting siRNAs as secondary regulators of gene expression in plants}

Intensive cloning efforts in plants have revealed that the great majority of endogenous small RNAs are DCL3-processed 24-nt cis-acting siRNAs that derive from heterochromatin, transposons and repeat elements (Reinhart et al. 2002; Xie et al. 2004; Gustafson et al. 2005; Lu et al. 2005). Another class corresponds to DCL1-processed miRNAs that derive from $M I R$ genes, and a third class corresponds to DCL4-processed trans-acting siRNAs (tasiRNAs) that derive from TAS genes (Peragine et al. 2004; Vazquez et al. 2004b; Allen et al. 2005). TAS genes transcribe long primary RNAs that are not predicted to encode proteins and seem to function by serving as the precursors for ta-siRNA production (Fig. 2). TAS primary RNAs are cleaved by specific miRNAs so the production of ta-siRNAs requires AGO1, DCL1, HEN1, and HYL1 (Peragine et al. 2004; Vazquez et al. 2004b; Allen et al. 2005). The production of ta-siRNAs also requires SGS3 and RDR6, which transform one of the two single-stranded TAS cleavage products into dsRNA (Peragine et al. 2004; Vazquez et al. 2004b; Allen et al. 2005). RDR6-derived TAS dsRNAs are sequentially processed into 21-nt ta-siRNAs by DCL4 (Gasciolli et al. 2005; Xie et al. 2005b; Yoshikawa et al. 2005), which associates with the dsRNAbinding protein DRB4 (Hiraguri et al. 2005; Adenot et al. 2006), starting from the miRNA-cleaved end of the TAS precursors, to generate clusters of ta-siRNAs (Vazquez et al. 2004b; Allen et al. 2005; Yoshikawa et al. 2005). 
Like miRNAs, ta-siRNAs are methylated by HEN1 (Li et al. 2005), and like miRNAs, the $5^{\prime}$ half of ta-siRNAs shows a high level of complementarity with endogenous mRNAs. ta-siRNAs regulate the expression of their target mRNAs by guiding mRNA cleavage (Peragine et al. 2004; Vazquez et al. 2004b; Allen et al. 2005). Interestingly, different members of the same gene family can be targeted by either miRNAs or ta-siRNAs. For example, members of the same PPR subfamily are targeted by either miR161 or TAS2 ta-siRNAs (Rhoades et al. 2002; Allen et al. 2005; Yoshikawa et al. 2005). In addition, members of the ARF family are targeted by either miR160, miR167, or TAS3 ta-siRNAs (Rhoades et al. 2002; Allen et al. 2005). Like some miRNAs, some tasiRNAs may act in the nucleus, as suggested by the complementarity of one of the TAS1a-derived ta-siRNAs with the intron of the At2g46740 pre-mRNA, which encodes an FAD-binding domain-containing protein, and the elevated level of unspliced At2g46740 RNA in tasiRNA-deficient mutants (Vazquez et al. 2004b). It is likely that AGO1 is responsible for cleaving mRNAs targeted by TAS1 ta-siRNAs because TAS1 ta-siRNAs associate with AGO1 in vitro (Baumberger and Baulcombe 2005; Qi et al. 2005). AGO1 also seems to be involved in TAS2-mediated regulation, whereas AGO7 seems to be involved in TAS3-mediated regulation. Indeed, ago7 mutants show reduced levels of TAS3 ta-siRNAs, but not of TAS1 or TAS2 ta-siRNAs, and elevated levels of TAS3 ta-siRNA targets, but not of TAS1 or TAS2 ta-siRNA targets (Peragine et al. 2004; Allen et al. 2005; Adenot et al. 2006). Whether ta-siRNAs also exist in animals has not been reported.

\section{Natural cis-acting siRNAs as specific regulators of gene expression in plants}

An additional class of endogenous siRNAs (nat-siRNAs), which derives from pairs of natural cis-antisense transcripts, was recently discovered in Arabidopsis, revealing an endogenous function for DCL2 (Borsani et al. 2005). In the case examined, one transcript is expressed constitutively whereas the other is induced by salt treatment. When both transcripts are present, a stable 24-nt nat-siRNA deriving from the region of complementary and corresponding to the induced transcript is produced through the action of DCL2, NRPD1a, RDR6, and SGS3 (Fig. 2). This 24-nt nat-siRNA guides the cleavage of the constitutive transcript and establishes a phase for the sequential production of 21-nt nat-siRNAs by DCL1 and further cleavage of the constitutive transcript. However, the production of these 21-nt nat-siRNAs does not appear to be required for down-regulating the constitutive transcript because $d c 11$ mutants that accumulate the 24nt nat-siRNA but not the 21-nt nat-siRNAs exhibit transcript levels similar to those of wild-type plants. Therefore, unlike 21-nt ta-siRNAs that have a functional role in targeting unlinked transcripts, 21-nt nat-siRNAs may only be produced to ensure cleavage in cis. There are 2000 pairs of natural cis-antisense transcripts in Arabidopsis (Wang et al. 2005). nat-siRNAs corresponding to other cis-antisense transcript pairs exist and are detected only under inducible conditions, suggesting that this type of regulation may not be restricted to a single example of overlapping transcripts (Borsani et al. 2005).

\section{Regulation of the miRNA and ta-siRNA pathways by miRNAs and ta-siRNAs}

Two miRNAs, miR162 and miR168, are involved in the regulation of the miRNA pathway itself by guiding cleavage of DCL1 and AGO1 mRNAs, respectively (Rhoades et al. 2002; Xie et al. 2003; Vazquez et al. 2004a). Such feedback regulation of the two major actors of the miRNA pathway is probably essential to maintain a proper balance of miRNA steady-state levels, which depends on both miRNA production by DCL1 and miRNA turn-over during AGO1-catalyzed mRNA cleavage. Indeed, analysis of miRNA levels in ago1 mutants has revealed that most miRNAs were unstable in the absence of AGO1 protein, pointing to a stabilization role of AGO1 in addition to its catalytic role (Vaucheret et al. 2004). Expression of a miR168-resistant AGO1 mRNA results in an increased AGO1 level and in increased accumulation of some miRNAs, in particular miR168, suggesting that AGO1 is normally limiting, and that the level of AGO1 is maintained in equilibrium by the dual effect of miR168 on AGO1 mRNA and of AGO1 protein on miR168 (Vaucheret et al. 2006).

Because ta-siRNAs are sequentially processed from long dsRNAs, which result from the transformation of the primary TAS single-stranded RNA (ssRNA) into dsRNA by RDR6, ta-siRNA duplexes contain both the strand corresponding to the primary TAS RNA and the strand complementary to the primary TAS RNA (Peragine et al. 2004; Vazquez et al. 2004b; Allen et al. 2005). Like miRNAs, ta-siRNAs obey the asymmetry rule (the strand of the duplex that has the lowest stability at its $5^{\prime}$ end accumulates), whereas the passenger strand is degraded (Vazquez et al. 2004b; Allen et al. 2005). Like miRNAs, mature ta-siRNAs deriving from the $(+)$ strand (which corresponds to the primary TAS RNA) target genes that show little resemblance with the TAS genes (Peragine et al. 2004; Vazquez et al. 2004b; Allen et al. 2005). However, mature ta-siRNAs deriving from the (-) strand (which is complementary to the primary TAS RNA) have the potential to target and regulate the primary TAS RNA. An overaccumulation of primary TAS RNA was observed in ta-siRNA-deficient mutants, pointing to a locus-specific feedback regulation that allows the maintenance of ta-siRNA steady-state levels (Vazquez et al. 2004b).

\section{Open questions}

How many miRNAs, ta-siRNAs, and nat-siRNAs exist?

MIR and TAS genes, as well as the cis-antisense gene pairs that generate nat-siRNAs, have some of the char- 
acteristics of other plant genes; i.e., they are transcribed by DNA-dependent RNA polymerase II into capped and polyadenylated RNAs (Parizotto et al. 2004; Vazquez et al. 2004b; Allen et al. 2005; Xie et al. 2005a; Yoshikawa et al. 2005). However, because MIR and TAS genes do not contain obvious signatures such as the ORF of protein coding genes, they cannot be predicted with confidence from the genome sequence using this criterion alone. Although the minimal folding free energy index for miRNA precursors is significantly higher than tRNAs, rRNAs, or mRNAs (Zhang et al. 2006b), searching for genomic sequences that have the potential to form foldback stem-loop structures similar to that of miRNA precursors is insufficient, as 138,864 inverted repeat structures exist in the Arabidopsis genome (Jones-Rhoades and Bartel 2004). Bioinformatic predictions that rely on the conservation of fold-back stem-loop structures between monocot and dicot species have been successful at identifying MIR genes that have been conserved after the divergence of monocot and dicot species (Jones-Rhoades and Bartel 2004). Young MIR genes that are species specific are more difficult to predict using bioinformatics tools. However, because MIR genes and their targets are assumed to derive from the same ancestor gene by inverted-repeat duplication, young $M I R$ genes exhibit greater homology with their targets beyond the miRNA and miRNA complementary sequences (Allen et al. 2004), a criterion that could be helpful for identifying species-specific $M I R$ genes. In addition, TAS genes have not been predicted successfully from the genome sequence because ta-siRNAs derive from ssRNAs that do not exhibit any known signatures that indicate how they are transformed into dsRNAs by RNA-dependent RNA polymerases. Cis-antisense gene pairs can be identified from annotated genomes; however, the rules that regulate the production of nat-siRNAs are not known. Therefore, the most reliable way to identify miRNAs, tasiRNAs, and nat-siRNAs is the intensive cloning of small RNAs isolated from samples representing all tissues, all stages of life of the organism, and all conditions of growth, followed by the computational analysis of their arrangement within the genome. MIR genes can be confidently predicted when two collinear 21-nt small RNAs that are partially complementary are found 50$250 \mathrm{nt}$ from each other, which is the size range of most MIR loops in plants, with a 10:1 ratio, which is the usual ratio between miRNA and miRNA*, owing to the degradation of miRNA* sequences, which are not stabilized in RISC. TAS genes can be confidently predicted when multiple small RNAs are found in 21-nt increments, originating from both DNA strands, including pairs of perfectly complementary molecules. Genetic confirmation of the nature of the small RNAs can be obtained in model species such as Arabidopsis or rice (Table 2). Intensive small RNA sequencing has been performed in Arabidopsis using MPSS; however, MPSS only provides a 17-nt sequence, which does not always allow the assignment of a confident genomic location to the small RNA because of the uncertainty about the last 4-7 nt. Nevertheless, 70,000 unique sequences were identified
Table 2. Genetic requirements of endogenous small RNAs in plants

\begin{tabular}{lccccccc}
\hline $\begin{array}{c}\text { Small } \\
\text { RNA }\end{array}$ & $\begin{array}{c}\text { Size } \\
\text { (nt) }\end{array}$ & DCL1 & DCL2 & DCL3 & DCL4 & RDR2 & RDR6 \\
\hline miRNA & 21 & + & - & - & - & - & - \\
ta-siRNA & 21 & + & - & - & + & - & + \\
nat-siRNA & 24 & - & + & - & - & - & + \\
nat-siRNA & 21 & + & + & - & - & - & + \\
hc-siRNA & 24 & - & - & + & - & + & - \\
\hline
\end{tabular}

The size indicated corresponds to the major accumulating species of small RNA. miRNA size ranges from 20 to $24 \mathrm{nt}$. tasiRNA size ranges from 20 to $22 \mathrm{nt}$. hc-siRNA size ranges from 21 to $24 \mathrm{nt}$. A plus sign (+) indicates that the enzyme is required. A minus sign (-) indicates that the enzyme is dispensable.

from 1,500,000 MPSS reads, revealing complexity to the small RNA repertoire in plants (Lu et al. 2005). However, this analysis did not reveal an abundant number of additional MIR or TAS genes. In addition, this set of small RNAs did not contain the nat-siRNAs because they are only expressed under particular conditions of growth (Borsani et al. 2005). It is likely that the sequencing of a larger number of small RNAs from other sources of material will reveal rare or tissue-specific miRNAs, ta-siRNAs, nat-siRNAs, and heterochromatin/repeat sequence siRNAs that have been missed so far.

\section{How are MIR and TAS genes regulated?}

MicroRNAs and ta-siRNAs impose a regulation on their targets that has important consequences on gene expression and often determines changes in cell fate (Bartel 2004). Although the regulation of MIR and TAS genes is critical for proper regulation of their targets, little is known about the expression patterns of MIR and TAS genes in plants, whereas the tissue-specific expression of animal miRNAs has been extensively analyzed (Wienholds et al. 2005). In situ hybridizations have revealed that miR165/166 and miR172 accumulate in a tissuespecific manner (Chen 2004; Kidner and Martienssen 2004); however, the basis of this tissue-specific accumulation is unknown. Fusions between MIR164c and MIR171 promoters and reporter genes also have revealed tissue-specific expression, suggesting that part of the regulation of MIR164c and MIR171 genes occurs at the transcription level (Parizotto et al. 2004; Baker et al. 2005). Post-transcriptional regulations likely play additional roles. Indeed, mutations in the SERRATE (SE) gene encoding a zinc-finger protein result in $\mathrm{miR} 165 / 166$ precursor overaccumulation and reduced mature miR165/166 accumulation, indicating that SE is required for post-transcriptional regulation of MIR165 and MIR166 genes (Grigg et al. 2005). Clearly, most regulations of $M I R$ and TAS genes remain to be identified.

\section{Are miRNAs, ta-siRNAs, and nat-siRNAs mobile?}

Transgene PTGS mediated by siRNAs in plants is not cell autonomous. After local triggering, either spontaneously or artificially, PTGS spreads systemically from cell 
to cell via plasmodesmata and at long distance through the vascular tissues (Palauqui et al. 1997; Voinnet et al. 1998). Although siRNAs have not been formerly identified as the mobile silencing signal, the 21-nt transgenederived siRNAs produced by DCL4 are likely to be mobile and responsible for at least cell-to-cell propagation of PTGS because $d c 14$ mutants fail to exhibit short distance spreading of PTGS triggered by a vascular-specific promoter (Dunoyer et al. 2005). If transgene-derived 21-nt siRNAs are mobile, are endogenous 21-nt miRNAs, 21nt ta-siRNAs, and 21-nt nat-siRNAs also mobile? The tissue-specific accumulation of miR165/166 and miR172 revealed by in situ hybridizations suggests that these miRNAs are not mobile (Chen 2004; Kidner and Martienssen 2004) or at least do not accumulate at distances far from their production, although there could be limited mobility within a given tissue. However, some miRNAs-miR156, miR159, and miR167-have been cloned from vascular tissues, suggesting that some miRNAs could move within certain parts of the plant (Yoo et al. 2004). It is possible that miRNAs are transported from a distant source and only accumulate within tissues where stabilizing factors are present. In addition, it is likely that small RNAs are not mobile as free molecules and that their mobility depends on their association with particular proteins, which itself could depend on their mode of biogenesis. Whether the tissue-specific accumulation of miRNAs, ta-siRNAs, or nat-siRNAs is modified in mutants impaired in the movement of transgene-derived siRNAs will likely shed light on this important question.

What is the contribution of translation repression versus $m R N A$ cleavage?

MicroRNA-mediated translational repression in animals was originally proposed to have no effect on mRNA stability; however, recent reports have shown that mRNA accumulation is also affected (Bagga et al. 2005; Lim et al. 2005). In plants, miRNA-mediated regulation is assumed to occur almost exclusively by cleavage (Llave et al. 2002; Kasschau et al. 2003). However, protein levels have only been analyzed in the case of miR172-mediated regulation of $A P 2$, and there was no correlation between $A P 2$ mRNA and AP2 protein levels. Rather, the amount of AP2 mRNA was unchanged when the level of miR172 was either decreased (in dcl1 or hen1 mutants) or elevated (in plants overexpressing miR172 under the control of the strong $35 \mathrm{~S}$ promoter), whereas the amount of AP2 protein inversely correlated with the amount of miR172 (Aukerman and Sakai 2003; Chen 2004). This prompted the proposal that miR172-mediated regulation of $A P 2$ was occurring by translational repression, although AP2 had no distinguishing features when compared with the other miRNA targets, and although $5^{\prime}$ RACE indicated that, like other miR172 targets, AP2 mRNA was cleaved in the middle of the region of complementarity with miR172 (Aukerman and Sakai 2003; Kasschau et al. 2003; Lauter et al. 2005). Qualitative PCR using an AP2 cleavage-specific adapter showed that, although AP2 mRNA remained constant, cleavage actually was increased in 35S-MIR172 plants (Schwab et al. 2005). This led to the suggestion that AP2 was regulating its own transcription and that the unchanged $A P 2$ mRNA level in 35S-MIR172 plants resulted from increased cleavage, which led to reduced AP2 protein levels and increased transcription of the AP2 gene. However, this hypothesis does not rule out the possibility that translational repression occurs in plants. Additional analyses of both mRNA and protein levels of other miRNA targets are required before this question can be answered. In addition, it is possible that plant miRNA targets that are regulated by translational repression have not been identified yet. Indeed, translational repression in animals is mediated by small segments of complementarity corresponding to the "seed" region of miRNAs; i.e., between bases 2 and 8 (Bartel 2004). Since the prediction of miRNA targets in plants is based on longer segments of complementarity with miRNAs, the existing list of miRNA targets does not contain genes with shorter segments of complementarity because they are not distinguishable from background noise in bioinformatics analyses (Rhoades et al. 2002; Jones-Rhoades and Bartel 2004). Genome-wide transcriptome analyses of plants overexpressing several miRNAs did not reveal an abundance of additional targets (Schwab et al. 2005). However, this may be because translational repression has only a subtle effect on mRNA accumulation. Comparing the transcriptome to the proteome in plants overexpressing miRNAs or in miRNA-deficient mutants may help identify targets regulated by translational repression.

Why are TAS cleavage products transformed into dsRNA after miRNA-mediated cleavage, whereas cleavage products deriving from other miRNA targets are not?

A unique feature of TAS transcripts is that after miRNAguided cleavage, one of the two cleavage products is transformed into dsRNA by RDR6, and sequentially processed into 21-nt ta-siRNAs by DCL4 (Peragine et al. 2004; Vazquez et al. 2004b; Allen et al. 2005; Gasciolli et al. 2005; Xie et al. 2005b; Yoshikawa et al. 2005). Largescale cloning of small RNAs from Arabidopsis has not revealed an abundance of small RNAs deriving from miRNA targets, except for the TAS transcripts targeted by miR173 and miR390, indicating that not all miRNAderived cleavage products enter this pathway (Lu et al. 2005). The basis of the specificity of RDR6 for TAS-derived cleavage products is unclear, as is unclear the reason why only one TAS-derived cleavage products is transformed into dsRNA and why, depending on the TAS locus considered, either the $5^{\prime}$ or $3^{\prime}$ cleavage product is used as substrate. The fact that TAS RNAs are non-protein-coding RNAs, whereas other miRNA targets are translated into proteins does not seem to be the reason. Indeed, 35S-driven transgenes transcribing a translatable GFP RNA with a miRNA complementary site produces 
siRNAs after miRNA-guided cleavage that lead to consistent PTGS of the GFP transgenes in wild-type transformants, whereas only miRNA-guided cleavage of GFP RNAs occurs in rdr6 transformants (Parizotto et al. 2004). The production of GFP siRNAs does not seem to result exclusively from high levels of transcription due to the $35 \mathrm{~S}$ promoter. Indeed, whereas introduction of an extra-copy of a wild-type gene usually does not trigger PTGS of the endogenous copy, introduction of an extracopy of the wild-type $A G O 1$ gene, which is targeted by miR168, leads to PTGS of the endogenous AGO1 gene in $\sim 20 \%$ of wild-type transformants but never occurs in rdr6 transformants or in wild-type plants transformed with an AGO1 gene mutated in the miR168 complementary site (Vaucheret et al. 2004). The subcellular location of the target genes may play a role by determining the ability of transcribed RNAs to become a substrate for RDR6. The accumulation of miR173 and miR390, the two miRNAs that target TAS primary RNAs, is unchanged in hst mutants (Xie et al. 2005a), suggesting that these miRNAs act in the nucleus. It is likely that the entire ta-siRNA pathway occurs in the nucleus because DCL4, which processes RDR6-derived dsRNAs, is located in the nucleus (Hiraguri et al. 2005) and because the accumulation of ta-siRNAs is unchanged in hst mutants (Allen et al. 2005; Park et al. 2005), suggesting that TAS primary transcripts are not exported to the cytoplasm. Other miRNA target mRNAs may be efficiently exported to the cytoplasm and translated into proteins or cleaved by miRNA-guided AGO1. If RDR6 is in the nucleus while cleavage products are in the cytoplasm, no ta-siRNAs can be produced. Only in ectopic cases where transgene-derived RNAs may not be efficiently exported to the cytoplasm due to their particular genomic location or high abundance does the probability that miRNA-guided cleavage occurs in the nucleus increase, leading to PTGS of homologous transgene and endogenous RNAs.

\section{How does DCL2 produce the initial 24-nt nat-siRNA?}

Cis-antisense gene pairs produce transcripts that have a long region of complementarity. In the example analyzed by Zhu and colleagues (Borsani et al. 2005), the processing of this long dsRNA by DCL2 produces only one 24-nt nat-siRNA, which subsequently guides the cleavage of one of the two transcripts to set the frame for the production of 21-nt nat-siRNAs by DCL1. DCL1-mediated production of 21-nt nat-siRNAs in frame with the 24-nt nat-siRNA-guided cleavage site resembles DCL4-mediated production of 21-nt ta-siRNAs in frame with the miRNA-guided cleavage site on the TAS transcripts. However, it is unclear how the cis-antisense gene pairderived long dsRNA is processed into a single 24-nt natsiRNA by DCL2. It is possible that DCL2 has the ability to perform sequence-specific endonucleolytic cleavages of long perfect dsRNA whereas DCL4 and DCL1 likely process long dsRNA sequentially, starting from one end. However, DCL1 also is able to perform sequence-specific endonucleolytic cleavages of partially folded miRNA precursors to produce miRNA duplexes. The sequence and structural requirements for DCL-mediated endonucleolytic cleavages remains to be determined.

\section{What is the role of SiRNA- and miRNA-directed methylation?}

Endogenous or transgene-derived siRNAs that correspond to promoter sequences guide DNA methylation in homologous promoter sequences, which is assumed to be, at least in part, responsible for TGS (Mette et al. 2000; Matzke et al. 2001; Chan et al. 2004). In addition to guiding mRNA degradation during PTGS, transgene-derived siRNAs that correspond to transcribed sequences also guide DNA methylation in the homologous transgene sequence (Matzke et al. 2001; Vance and Vaucheret 2001; Baulcombe 2004). However, methylation in the transcribed sequence does not seem to influence transcription because transgene transcription rates have been found similar in wild-type (silenced) plants and ago1, rdr6, or sgs3 (nonsilenced) mutants (Mourrain et al. 2000; Morel et al. 2002). Therefore, the incidence and the role of methylation associated with PTGS remains unclear. Interestingly, $P H B$ and $P H V$ genes, which are regulated by miR165/166, are specifically methylated downstream of the miRNA complementary site (Bao et al. 2004). Indeed, $P H B$ and $P H V$ are not methylated in serrate mutants that are defective in the production of miR165/166 and in $p h b$ and $p h v$ mutants carrying $P H B$ or PHV genes mutated in the miRNA complementary site (Bao et al. 2004; Grigg et al. 2005). Heterozygous $\mathrm{PHB} / \mathrm{phb}$ or $\mathrm{PHV} / \mathrm{ph}$ v plants that carry both a wild-type allele and a mutant target allele are only methylated in the wild-type allele, suggesting that DNA methylation occurs in cis and depends on the ability of the miRNA to bind to the transcribed RNAs (Bao et al. 2004). The incidence and the role of methylation associated with miRNAs also are unclear, as is unclear why methylation occurs downstream of the miRNA complementary site. Methylation-deficient mutants exist in Arabidopsis (Chan et al. 2005), but these mutants have not been reported to have developmental abnormalities that could result from defects in $P H B$ or $P H V$ expression; however, the methylation status of $P H B$ and $P H V$ has not been examined in these mutants. Whether other genes that are repressed by miRNAs are methylated is unknown. It also is unknown if ta-siRNAs or nat-siRNAs, which resemble transgene-derived siRNAs, trigger the methylation of the TAS genes or the cis-antisense gene pairs from which they derive, respectively, and if such methylation could play a role in their regulation.

\section{Why do viruses inhibit the miRNA pathway?}

Most viruses express proteins that are able to inhibit PTGS to some extent (Vance and Vaucheret 2001; Baulcombe 2004; Dunoyer and Voinnet 2005; Li and Ding 2005). Coinoculation of a virulent virus (i.e., a virus that 
strongly inhibits PTGS) with a mild virus (i.e., a virus that weakly inhibits PTGS) results in increased symptoms, a phenomenon known as synergism (Pruss et al. 1997). This observation has led to the hypothesis that virus-mediated counteraction of the plant PTGS defenses is necessary to establish efficient systemic infections (Vance and Vaucheret 2001; Baulcombe 2004; Dunoyer and Voinnet 2005; Li and Ding 2005), consistent with the accentuation of viral symptoms observed in PTGS-deficient mutants (Mourrain et al. 2000; Dalmay et al. 2001; Qu et al. 2005; Schwach et al. 2005). Viruses also inhibit transgene-induced PTGS because the production and action of transgene-derived siRNAs is likely similar to the production and action of virus-derived siRNAs (Vance and Vaucheret 2001; Baulcombe 2004; Dunoyer and Voinnet 2005; Li and Ding 2005). Viruses also inhibit the miRNA pathway to some extent (Mallory et al. 2002; Kasschau et al. 2003; Chapman et al. 2004; Dunoyer et al. 2004). Whether viruses inhibit the miRNA pathway because the miRNA and siRNA pathways share common components or because the miRNA pathway directly or indirectly impacts virus infection is unknown. Several near-perfect homologies between plant small RNAs and viral genomes have been reported, suggesting that viruses could be targeted by endogenous small RNAs (Llave 2004); however, there are no experimental data supporting this hypothesis. Studies in human cells have revealed that an endogenous miRNA, miR32, targets the retrovirus PFV-1, suggesting that miRNAs may have an antiviral role (Lecellier et al. 2005). On the other hand, attempts to control virus proliferation by introduction of artificial siRNAs into virusinfected human cells resulted in the appearance of mutations in the siRNA complementarity site of the virus that are compatible with the life cycle of the viruses $(\mathrm{Li}$ and Ding 2005). Therefore, if it happened by chance that plant miRNAs were able to target viral RNAs, it is likely that the corresponding viruses would mutate to escape targeting in order to successfully infect plants (SimonMateo and Garcia 2006). It also is possible that viruses inhibit the miRNA pathway because the up-regulation of some miRNA targets provides favorable conditions for virus proliferation. So far, none of the known miRNA targets have been shown to directly control virus proliferation. However, many miRNA targets encode transcription factors that regulate a large number of unknown genes (Rhoades et al. 2002; Jones-Rhoades and Bartel 2004), among which could be a gene controlling virus proliferation.

The questions asked in this review only represent a small fraction of the questions that researchers in the RNAi field are currently trying to answer. Given the formidable expansion of investigation in this recent subject, it is likely that many questions will find their answers in the near future through the crossing approaches of developmental biologists, biochemists, and virologists. However, the apparent complexity of small RNArelated pathways also increases as we gain further insights into their mechanisms, raising more and more questions.

\section{Acknowledgments}

I thank Allison Mallory for critical reading of the manuscript and David Bartel and members of the Vaucheret and Bartel laboratories for fruitful discussions. I apologize for colleagues whose work has not been cited owing to space limitation. Work in the Vaucheret laboratory is supported by INRA and the European Commission (Riboreg program).

\section{References}

Adenot, X., Elmayan, T., Lauressergues, D., Boutet, S., Bouché, N., Gasciolli, V., and Vaucheret, H. 2006. Uncoupled production of ta-siRNAs in hypomorphic $r d r 6$ and sgs 3 mutants uncovers a role for TAS3 in AGO7-DCL4-DRB4-mediated control of leaf mophology. Curr. Biol. (in press).

Allen, E., Xie, Z., Gustafson, A.M., Sung, G.H., Spatafora, J.W., and Carrington, J.C. 2004. Evolution of microRNA genes by inverted duplication of target gene sequences in Arabidopsis thaliana. Nat. Genet. 36: 1282-1290.

Allen, E., Xie, Z., Gustafson, A.M., and Carrington, J.C. 2005. microRNA-directed phasing during trans-acting siRNA biogenesis in plants. Cell 121: 207-221.

Ambros, V. 2004. The functions of animal microRNAs. Nature 431: 350-355.

Aukerman, M.J. and Sakai, H. 2003. Regulation of flowering time and floral organ identity by a microRNA and its APETALA2-like target genes. Plant Cell 15: 2730-2741.

Bagga, S., Bracht, J., Hunter, S., Massirer, K., Holtz, J., Eachus, R., and Pasquinelli, A.E. 2005. Regulation by let-7 and lin-4 miRNAs results in target mRNA degradation. Cell 122: 553 563.

Baker, C.C., Sieber, P., Wellmer, F., and Meyerowitz, E.M. 2005. The early extra petals1 mutant uncovers a role for microRNA miR164c in regulating petal number in Arabidopsis. Curr. Biol. 15: 303-315.

Bao, N., Lye, K.W., and Barton, M.K. 2004. MicroRNA binding sites in Arabidopsis class III HD-ZIP mRNAs are required for methylation of the template chromosome. Dev. Cell 7: 653-662.

Bartel, D.P. 2004. MicroRNAs: Genomics, biogenesis, mechanism, and function. Cell 116: 281-297.

Baulcombe, D. 2004. RNA silencing in plants. Nature 431: 356363.

Baumberger, N. and Baulcombe, D.C. 2005. Arabidopsis ARGONAUTE1 is an RNA Slicer that selectively recruits microRNAs and short interfering RNAs. Proc. Natl. Acad. Sci. 102: 11928-11933.

Beclin, C., Boutet, S., Waterhouse, P., and Vaucheret, H. 2002. A branched pathway for transgene-induced RNA silencing in plants. Curr. Biol. 12: 684-688.

Bohmert, K., Camus, I., Bellini, C., Bouchez, D., Caboche, M., and Benning, C. 1998. AGO1 defines a novel locus of Arabidopsis controlling leaf development. EMBO J. 17: 170-180.

Borsani, O., Zhu, J., Verslues, P.E., Sunkar, R., and Zhu, J.K. 2005. Endogenous siRNAs derived from a pair of natural cis-antisense transcripts regulate salt tolerance in Arabidopsis. Cell 123: 1279-1291.

Boutet, S., Vazquez, F., Liu, J., Béclin, C., Fagard, M., Gratias, A., Morel, J.B., Crété, P., Chen, X., and Vaucheret, H. 2003. Arabidopsis HEN1: A genetic link between endogenous miRNA controlling development and siRNA controlling transgene silencing and virus resistance. Curr. Biol. 13: 843-848.

Brennecke, J., Hipfner, D.R., Stark, A., Russell, R.B., and Cohen, S.M. 2003. bantam encodes a developmentally regulated microRNA that controls cell proliferation and regulates the 
proapoptotic gene hid in Drosophila. Cell 113: 25-36.

Carrington, J.C. and Ambros, V. 2003. Role of microRNAs in plant and animal development. Science 301: 336-338.

Chan, S.W., Zilberman, D., Xie, Z., Johansen, L.K., Carrington, J.C., and Jacobsen, S.E. 2004. RNA silencing genes control de novo DNA methylation. Science 303: 1336.

Chan, S.W., Henderson, I.R., and Jacobsen, S.E. 2005. Gardening the genome: DNA methylation in Arabidopsis thaliana. Nat. Rev. Genet. 6: 351-360.

Chapman, E.J., Prokhnevsky, A.I., Gopinath, K., Dolja, V.V., and Carrington, J.C. 2004. Viral RNA silencing suppressors inhibit the microRNA pathway at an intermediate step. Genes \& Dev. 18: 1179-1186.

Chen, X. 2004. A microRNA as a translational repressor of APETALA2 in Arabidopsis flower development. Science 303: 2022-2025.

- 2005. MicroRNA biogenesis and function in plants. FEBS Lett. 579: 5923-5931.

Chen, X., Liu, J., Cheng, Y., and Jia, D. 2002. HEN1 functions pleiotropically in Arabidopsis development and acts in C function in the flower. Development 129: 1085-1094.

Dalmay, T., Hamilton, A., Rudd, S., Angell, S., and Baulcombe, D.C. 2000. An RNA-dependent RNA polymerase gene in Arabidopsis is required for posttranscriptional gene silencing mediated by a transgene but not by a virus. Cell 101: 543-553.

Dalmay, T., Horsefield, R., Braunstein, T.H., and Baulcombe, D.C. 2001. SDE3 encodes an RNA helicase required for posttranscriptional gene silencing in Arabidopsis. EMBO J. 20: 2069-2078.

Du, T. and Zamore, P.D. 2005. microPrimer: The biogenesis and function of microRNA. Development 132: 4645-4652.

Dunoyer, P. and Voinnet, O. 2005. The complex interplay between plant viruses and host RNA-silencing pathways. Curr. Opin. Plant Biol. 8: 415-423.

Dunoyer, P., Lecellier, C.H., Parizotto, E.A., Himber, C., and Voinnet, O. 2004. Probing the microRNA and small interfering RNA pathways with virus-encoded suppressors of RNA silencing. Plant Cell 16: 1235-1250.

Dunoyer, P., Himber, C., and Voinnet, O. 2005. DICER-LIKE 4 is required for RNA interference and produces the 21-nucleotide small interfering RNA component of the plant cell-tocell silencing signal. Nat. Genet. 37: 1356-1360.

Emery, J.F., Floyd, S.K., Alvarez, J., Eshed, Y., Hawker, N.P., Izhaki, A., Baum, S.F., and Bowman, J.L. 2003. Radial patterning of Arabidopsis shoots by class III HD-ZIP and KANADI genes. Curr. Biol. 13: 1768-1774.

Fujii, H., Chiou, T.J., Lin, S.I., Aung, K., and Zhu, J.K. 2005. A miRNA involved in phosphate-starvation response in Arabidopsis. Curr. Biol. 15: 2038-2043.

Gasciolli, V., Mallory, A.C., Bartel, D.P., and Vaucheret, H. 2005. Partially redundant functions of Arabidopsis DICERlike enzymes and a role for DCL4 in producing trans-acting siRNAs. Curr. Biol. 15: 1494-1500.

Glazov, E., Phillips, K., Budziszewski, G.J., Schob, H., Meins Jr., F., and Levin, J.Z. 2003. A gene encoding an RNase D exonuclease-like protein is required for post-transcriptional silencing in Arabidopsis. Plant J. 35: 342-349.

Grigg, S.P., Canales, C., Hay, A., and Tsiantis, M. 2005. SERRATE coordinates shoot meristem function and leaf axial patterning in Arabidopsis. Nature 437: 1022-1026.

Gustafson, A.M., Allen, E., Givan, S., Smith, D., Carrington, J.C., and Kasschau, K.D. 2005. ASRP: The Arabidopsis small RNA project database. Nucleic Acids Res. 33: D637-D640.

Hamilton, A.J. and Baulcombe, D.C. 1999. A species of small antisense RNA in posttranscriptional gene silencing in plants. Science 286: 950-952.

Han, M.H., Goud, S., Song, L., and Fedoroff, N. 2004. The Arabidopsis double-stranded RNA-binding protein HYL1 plays a role in microRNA-mediated gene regulation. Proc. Natl. Acad. Sci. 101: 1093-1098.

Herr, A.J., Jensen, M.B., Dalmay, T., and Baulcombe, D.C. 2005. RNA polymerase IV directs silencing of endogenous DNA. Science 308: 118-120.

Hiraguri, A., Itoh, R., Kondo, N., Nomura, Y., Aizawa, D., Murai, Y., Koiwa, H., Seki, M., Shinozaki, K., and Fukuhara, T. 2005. Specific interactions between Dicer-like proteins and HYL1/DRB-family dsRNA-binding proteins in Arabidopsis thaliana. Plant Mol. Biol. 57: 173-188.

Hunter, C., Sun, H., and Poethig, R.S. 2003. The Arabidopsis heterochronic gene ZIPPY is an ARGONAUTE family member. Curr. Biol. 13: 1734-1739.

Jones-Rhoades, M.W. and Bartel, D.P. 2004. Computational identification of plant miRNAs and their targets, including a stress-induced miRNA. Mol. Cell 14: 787-799.

Jones-Rhoades, M.W., Bartel, D.P., and Bartel, B. 2006. MicroRNAs and their regulatory roles in plants. Annu. Rev. Plant Biol. (in press).

Kasschau, K.D., Xie, Z., Allen, E., Llave, C., Chapman, E.J., Krizan, K.A., and Carrington, J.C. 2003. P1/HC-Pro, a viral suppressor of RNA silencing, interferes with Arabidopsis development and miRNA function. Dev. Cell 4: 205-217.

Ketting, R.F., Haverkamp, T.H., van Luenen, H.G., and Plasterk, R.H. 1999. Mut-7 of C. elegans, required for transposon silencing and RNA interference, is a homolog of Werner syndrome helicase and RNaseD. Cell 99: 133-141.

Kidner, C.A. and Martienssen, R.A. 2004. Spatially restricted microRNA directs leaf polarity through ARGONAUTE1. Nature 428: 81-84.

Kim, V.N. 2005. Small RNAs: Classification, biogenesis, and function. Mol. Cells 19: 1-15.

Kurihara, Y. and Watanabe, Y. 2004. Arabidopsis micro-RNA biogenesis through Dicer-like 1 protein functions. Proc. Natl. Acad. Sci. 101: 12753-12758.

Lauter, N., Kampani, A., Carlson, S., Goebel, M., and Moose, S.P. 2005. microRNA172 down-regulates glossy15 to promote vegetative phase change in maize. Proc. Natl. Acad. Sci. 102: 9412-9417.

Lecellier, C.H., Dunoyer, P., Arar, K., Lehmann-Che, J., Eyquem, S., Himber, C., Saib, A., and Voinnet, O. 2005. A cellular microRNA mediates antiviral defense in human cells. Science 308: 557-560.

Lee, R.C., Feinbaum, R.L., and Ambros, V. 1993. The C. elegans heterochronic gene lin-4 encodes small RNAs with antisense complementarity to lin-14. Cell 75: 843-854.

Li, H.W. and Ding, S.W. 2005. Antiviral silencing in animals. FEBS Lett. 579: 5965-5973.

Li, J., Yang, Z., Yu, B., Liu, J., and Chen, X. 2005. Methylation protects miRNAs and siRNAs from a 3 '-end uridylation activity in Arabidopsis. Curr. Biol. 15: 1501-1507.

Lim, L.P., Lau, N.C., Garrett-Engele, P., Grimson, A., Schelter, J.M., Castle, J., Bartel, D.P., Linsley, P.S., and Johnson, J.M. 2005. Microarray analysis shows that some microRNAs downregulate large numbers of target mRNAs. Nature 433: 769-773.

Linn, F., Heidmann, I., Saedler, H., and Meyer, P. 1990. Epigenetic changes in the expression of the maize Al gene in Petunia hybrida: Role of numbers of integrated gene copies and state of methylation. Mol. Gen. Genet. 222: 329-336.

Llave, C. 2004. MicroRNAs: More than a role in plant develop- 
ment? Mol. Plant Pathol. 5: 361-366.

Llave, C., Xie, Z., Kasschau, K.D., and Carrington, J.C. 2002. Cleavage of Scarecrow-like mRNA targets directed by a class of Arabidopsis miRNA. Science 297: 2053-2056.

Lu, C. and Fedoroff, N. 2000. A mutation in the Arabidopsis HYL1 gene encoding a dsRNA binding protein affects responses to abscisic acid, auxin, and cytokinin. Plant Cell 12: 2351-2366.

Lu, C., Tej, S.S., Luo, S., Haudenschild, C.D., Meyers, B.C., and Green, P.J. 2005. Elucidation of the small RNA component of the transcriptome. Science 309: 1567-1569.

Mallory, A.C., Reinhart, B.J., Bartel, D., Vance, V.B., and Bowman, L.H. 2002. A viral suppressor of RNA silencing differentially regulates the accumulation of short interfering RNAs and micro-RNAs in tobacco. Proc. Natl. Acad. Sci. 25: 25.

Mallory, A.C., Reinhart, B.J., Jones-Rhoades, M.W., Tang, G., Zamore, P.D., Barton, M.K., and Bartel, D.P. 2004. MicroRNA control of PHABULOSA in leaf development: Importance of pairing to the microRNA 5 ' region. $E M B O$ I. 23: 3356-3364.

Matzke, M.A., Primig, M., Trnovsky, J., and Matzke, A.J. 1989. Reversible methylation and inactivation of marker genes in sequentially transformed tobacco plants. EMBO J. 8: 643 649.

Matzke, M.A., Matzke, A.J., Pruss, G.J., and Vance, V.B. 2001. RNA-based silencing strategies in plants. Curr. Opin. Genet. Dev. 11: 221-227.

Mette, M.F., Aufsatz, W., van der Winden, J., Matzke, M.A., and Matzke, A.J. 2000. Transcriptional silencing and promoter methylation triggered by double-stranded RNA. EMBO J. 19: 5194-5201.

Morel, J.B., Godon, C., Mourrain, P., Beclin, C., Boutet, S., Feuerbach, F., Proux, F., and Vaucheret, H. 2002. Fertile hypomorphic ARGONAUTE (agol) mutants impaired in posttranscriptional gene silencing and virus resistance. Plant Cell 14: 629-639.

Mourrain, P., Beclin, C., Elmayan, T., Feuerbach, F., Godon, C., Morel, J.B., Jouette, D., Lacombe, A.M., Nikic, S., Picault, N., et al. 2000. Arabidopsis SGS2 and SGS3 genes are required for posttranscriptional gene silencing and natural virus resistance. Cell 101: 533-542.

Napoli, C., Lemieux, C., and Jorgensen, R. 1990. Introduction of a chimeric chalcone synthase gene into petunia results in reversible co-suppression of homologous genes in trans. Plant Cell 2: 279-289.

Palatnik, J.F., Allen, E., Wu, X., Schommer, C., Schwab, R., Carrington, J.C., and Weigel, D. 2003. Control of leaf morphogenesis by microRNAs. Nature 425: 257-263.

Palauqui, J.C., Elmayan, T., Pollien, J.M., and Vaucheret, H. 1997. Systemic acquired silencing: Transgene-specific posttranscriptional silencing is transmitted by grafting from silenced stocks to non-silenced scions. EMBO J. 16: 47384745.

Papp, I., Mette, M.F., Aufsatz, W., Daxinger, L., Schauer, S.E., Ray, A., Van Der Winden, J., Matzke, M., and Matzke, A.J. 2003. Evidence for nuclear processing of plant micro RNA and short interfering RNA precursors. Plant Physiol. 132: 1382-1390.

Parizotto, E.A., Dunoyer, P., Rahm, N., Himber, C., and Voinnet, O. 2004. In vivo investigation of the transcription, processing, endonucleolytic activity, and functional relevance of the spatial distribution of a plant miRNA. Genes \& Dev. 18: $2237-2242$.

Park, W., Li, J., Song, R., Messing, J., and Chen, X. 2002. CAR-
PEL FACTORY, a Dicer homolog, and HEN1, a novel protein, act in microRNA metabolism in Arabidopsis thaliana. Curr. Biol. 12: 1484-1495.

Park, M.Y., Wu, G., Gonzalez-Sulser, A., Vaucheret, H., and Poethig, R.S. 2005. Nuclear processing and export of microRNAs in Arabidopsis. Proc. Natl. Acad. Sci. 102: 3691-3696.

Peragine, A., Yoshikawa, M., Wu, G., Albrecht, H.L., and Poethig, R.S. 2004. SGS3 and SGS2/SDE1/RDR6 are required for juvenile development and the production of trans-acting siRNAs in Arabidopsis. Genes \& Dev. 18: 2368-2379.

Pruss, G., Ge, X., Shi, X.M., Carrington, J.C., and Bowman Vance, V. 1997. Plant viral synergism: The potyviral genome encodes a broad-range pathogenicity enhancer that transactivates replication of heterologous viruses. Plant Cell 9: 859868.

Qi, Y., Denli, A.M., and Hannon, G.J. 2005. Biochemical specialization within Arabidopsis RNA silencing pathways. Mol. Cell 19: 421-428.

Qu, F., Ye, X., Hou, G., Sato, S., Clemente, T.E., and Morris, T.J. 2005. RDR6 has a broad-spectrum but temperature-dependent antiviral defense role in Nicotiana benthamiana. J. Virol. 79: 15209-15217.

Reinhart, B.J., Slack, F.J., Basson, M., Pasquinelli, A.E., Bettinger, J.C., Rougvie, A.E., Horvitz, H.R., and Ruvkun, G. 2000. The 21-nucleotide let-7 RNA regulates developmental timing in Caenorhabditis elegans. Nature 403: 901-906.

Reinhart, B.J., Weinstein, E.G., Rhoades, M.W., Bartel, B., and Bartel, D.P. 2002. MicroRNAs in plants. Genes \& Dev. 16: 1616-1626.

Rhoades, M., Reinhart, B., Lim, L., Burge, C., Bartel, B., and Bartel, D. 2002. Prediction of plant microRNA targets. Cell 110: $513-520$

Schauer, S.E., Jacobsen, S.E., Meinke, D.W., and Ray, A. 2002. DICER-LIKE1: Blind men and elephants in Arabidopsis development. Trends Plant Sci. 7: 487-491.

Schwab, R., Palatnik, J.F., Riester, M., Schommer, C., Schmid, M., and Weigel, D. 2005. Specific effects of microRNAs on the plant transcriptome. Dev. Cell 8: 517-527.

Schwach, F., Vaistij, F.E., Jones, L., and Baulcombe, D.C. 2005. An RNA-dependent RNA polymerase prevents meristem invasion by potato virus $\mathrm{X}$ and is required for the activity but not the production of a systemic silencing signal. Plant Physiol. 138: 1842-1852.

Simon-Mateo, C. and Garcia, J.A. 2006. MicroRNA-guided processing impairs Plum pox virus replication, but the virus readily evolves to escape this silencing mechanism. J. Virol. 80: 2429-2436.

Smith, C.J., Watson, C.F., Bird, C.R., Ray, J., Schuch, W., and Grierson, D. 1990. Expression of a truncated tomato polygalacturonase gene inhibits expression of the endogenous gene in transgenic plants. Mol. Gen. Genet. 224: 477-481.

Smith, N.A., Singh, S.P., Wang, M.B., Stoutjesdijk, P.A., Green, A.G., and Waterhouse, P.M. 2000. Total silencing by intronspliced hairpin RNAs. Nature 407: 319-320.

Telfer, A. and Poethig, R.S. 1998. HASTY: A gene that regulates the timing of shoot maturation in Arabidopsis thaliana. Development 125: 1889-1898.

Tomari, Y. and Zamore, P.D. 2005. Perspective: Machines for RNAi. Genes \& Dev. 19: 517-529.

Vance, V. and Vaucheret, H. 2001. RNA silencing in plants: Defense and counterdefense. Science 292: 2277-2280.

van der Krol, A.R., Mur, L.A., Beld, M., Mol, J.N., and Stuitje, A.R. 1990. Flavonoid genes in petunia: Addition of a limited number of gene copies may lead to a suppression of gene expression. Plant Cell 2: 291-299. 
Vaucheret, H., Vazquez, F., Crété, P., and Bartel, D.P. 2004. The action of ARGONAUTE1 in the miRNA pathway and its regulation by the miRNA pathway are crucial for plant development. Genes \& Dev. 18: 1187-1197.

Vaucheret, H., Mallory, A.C., and Bartel, D.P. 2006. AGO1 homeostatis requires co-expression of MIR168 and AGO1, posttanscriptional stabilization of miR168 by AGO1, and miR168-guided AGO1 cleavage. Mol. Cell (in press).

Vazquez, F., Gasciolli, V., Crété, P., and Vaucheret, H. 2004a. The nuclear dsRNA binding protein HYL1 is required for microRNA accumulation and plant development, but not posttranscriptional transgene silencing. Curr. Biol. 14: 346351.

Vazquez, F., Vaucheret, H., Rajagopalan, R., Lepers, C., Gasciolli, V., Mallory, A.C., Hilbert, J.L., Bartel, D.P., and Crete, P. 2004b. Endogenous trans-acting siRNAs regulate the accumulation of Arabidopsis mRNAs. Mol. Cell 16: 69-79.

Voinnet, O., Vain, P., Angell, S., and Baulcombe, D.C. 1998. Systemic spread of sequence-specific transgene RNA degradation in plants is initiated by localized introduction of ectopic promoterless DNA. Cell 95: 177-187.

Wang, X.J., Gaasterland, T., and Chua, N.H. 2005. Genomewide prediction and identification of cis-natural antisense transcripts in Arabidopsis thaliana. Genome Biol. 6: R30.

Wienholds, E., Kloosterman, W.P., Miska, E., Alvarez-Saavedra, E., Berezikov, E., de Bruijn, E., Horvitz, H.R., Kauppinen, S., and Plasterk, R.H. 2005. MicroRNA expression in zebrafish embryonic development. Science 309: 310-311.

Xie, Z., Kasschau, K.D., and Carrington, J.C. 2003. Negative feedback regulation of Dicer-Like1 in Arabidopsis by microRNA-guided mRNA. Curr. Biol. 13: 784-789.

Xie, Z., Johansen, L.K., Gustafson, A.M., Kasschau, K.D., Lellis, A.D., Zilberman, D., Jacobsen, S.E., and Carrington, J.C. 2004. Genetic and functional diversification of small RNA pathways in plants. PLoS Biol. 2: 642-652.

Xie, Z., Allen, E., Fahlgren, N., Calamar, A., Givan, S.A., and Carrington, J.C. 2005a. Expression of Arabidopsis MIRNA genes. Plant Physiol. 138: 2145-2154.

Xie, Z., Allen, E., Wilken, A., and Carrington, J.C. 2005b. DICER-LIKE 4 functions in trans-acting small interfering RNA biogenesis and vegetative phase change in Arabidopsis thaliana. Proc. Natl. Acad. Sci. 102: 12984-12989.

Yekta, S., Shih, I.H., and Bartel, D.P. 2004. MicroRNA-directed cleavage of HOXB8 mRNA. Science 304: 594-596.

Yoo, B.C., Kragler, F., Varkonyi-Gasic, E., Haywood, V., ArcherEvans, S., Lee, Y.M., Lough, T.J., and Lucas, W.J. 2004. A systemic small RNA signaling system in plants. Plant Cell 16: 1979-2000.

Yoshikawa, M., Peragine, A., Park, M.Y., and Poethig, R.S. 2005. A pathway for the biogenesis of trans-acting siRNAs in Arabidopsis. Genes \& Dev. 19: 2164-2175.

Yu, D., Fan, B., MacFarlane, S.A., and Chen, Z. 2003. Analysis of the involvement of an inducible Arabidopsis RNA-dependent RNA polymerase in antiviral defense. Mol. Plant Microbe Interact. 16: 206-216.

Yu, B., Yang, Z., Li, J., Minakhina, S., Yang, M., Padgett, R.W., Steward, R., and Chen, X. 2005. Methylation as a crucial step in plant microRNA biogenesis. Science 307: 932-935.

Zhang, B., Pan, X., Cobb, G.P., and Anderson, T.A. 2006a. Plant microRNA: A small regulatory molecule with big impact. Dev. Biol. 289: 3-16.

Zhang, B.H., Pan, X.P., Cox, S.B., Cobb, G.P., and Anderson, T.A. 2006b. Evidence that miRNAs are different from other RNAs. Cell Mol. Life Sci. 63: 246-254. 


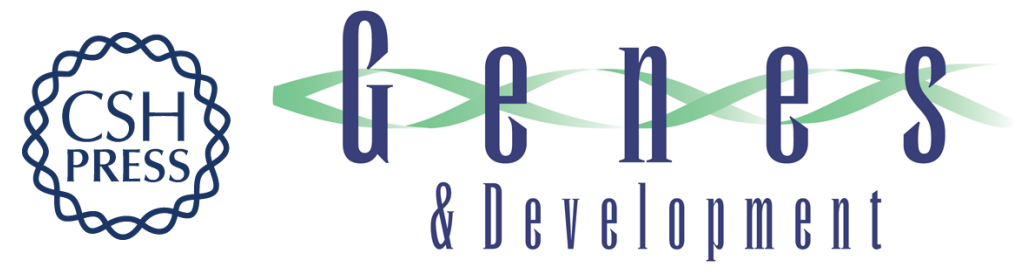

\title{
Post-transcriptional small RNA pathways in plants: mechanisms and regulations
}

\author{
Hervé Vaucheret
}

Genes Dev. 2006, 20:

Access the most recent version at doi:10.1101/gad.1410506
References This article cites 104 articles, 46 of which can be accessed free at: http://genesdev.cshlp.org/content/20/7/759.full.htmI\#ref-list-1

\section{License}
Email Alerting Service
Receive free email alerts when new articles cite this article - sign up in the box at the top right corner of the article or click here.

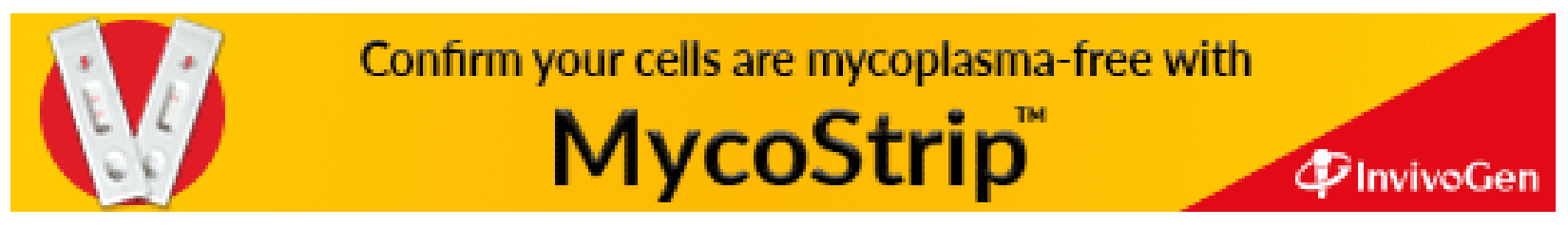

